\title{
PENERAPAN MODEL KLASIFIKASI METODE NAIVE BAYES TERHADAP PENGGUNAAN AKSES INTERNET
}

\author{
Heliyanti Susana $^{1)}$, Nana Suarna ${ }^{2)}$, Fathurrohman ${ }^{3)}$, Kaslani $^{4)}$ \\ ${ }^{1,2)}$ Program Studi Teknik Informatika STMIK IKMI Cirebon \\ Jl Perjuangan No 10B Kesambi Kota Cirebon \\ ${ }^{3)}$ Program Studi Rekayasa Perangkat Lunak STMIK IKMI Cirebon \\ Jl Perjuangan No 10B Kesambi Kota Cirebon \\ 4) Program Studi Komputerisasi Akuntansi STMIK IKMI Cirebon \\ Jl Perjuangan No 10B Kesambi Kota Cirebon \\ e-mail: heliheli@gmail.com ${ }^{1)}$, st nana@yahoo.com ${ }^{2)}$, fatur11@gmail.com ${ }^{3)}$, kaslani22@gmail.com ${ }^{4)}$ \\ * Korespondensi: e-mail : heliheli@gmail.com
}

\begin{abstract}
ABSTRAK
SMA $N 1$ Plumbon di peruntukkan untuk membantu dan memermudah siswa dalam belajar sehingga tidak kalah dengan kota-kota besar justru menjadikan siswa malas belajar dan meningkatkan ragam dari kenakalan siswa. bagaimana memodelkan klasifikasi dengan beberapa algoritma dalam studi kasus ini menerapkan algoritma nä̈ve bayes untuk menganalisa hak akses internet siswa, dari penerapan metode tersebut dapat dilihat akurasi kemudian dapat menganalisa pemakaian berdasarkan umur Nä̈ve Bayes merupakan salah satu metode machine learning yang menggunakan perhitungan probabilitas. Konsep dasar yang digunakan oleh Nä̈ve bayes adalah Teorema Bayes, yaitu melakukan klasifikasi dengan melakukan perhitungan nilai probabilitas hasil dari penelitian ini memiliki akurasi sebesar $89.83 \%$ Hasil Prediksi Ya dan ternyata Ya sebanyak 34. Hasil Prediksi Ya dan ternyata Tidak sebanyak 6. Hasil Prediksi tidak dan ternyata Ya sebanyak 0. Hasil Prediksi tidak dan ternyata tidak sebanyak 19. hasil dari prediksi dengan uji 59 data baru maka mendapatkan hasil ya sebanyak 40 siswa dan tidak ada 19 siswa
\end{abstract}

Kata Kunci: Datamining, Internet, Algoritma Nä̈ve Bayes

\begin{abstract}
SMA N 1 Plumbon is intended to help and facilitate students in learning so that they are not inferior to big cities, it makes students lazy to learn and increases the variety of student delinquency. How to model classification with several algorithms in this case study applies the nä̈ve Bayes algorithm to analyze students' internet access rights, from the application of this method, it can be seen the accuracy then can analyze usage based on age. Nä̈ve Bayes is a machine learning method that uses probability calculations. The basic concept used by Nä̈ve Bayes is the Bayes Theorem, which is to classify by calculating the probability value of the results of this study which has an accuracy of $72.88 \%$, namely the Prediction Results Yes and it turns out to be 22. Prediction Results Yes and not as many as 4. Prediction results are not and it turns out that Yes as many as 12. Prediction results are not and it turns out that there are not as many as 21. The results of the prediction by using 59 new data will get the results of yes as many as 26 students and no 33 students
\end{abstract}

Keywords: Datamining, Internet, Nä̈ve Bayes Algorithm. 


\section{Pendahuluan}

Internet merupakan salah satu hasil dari kecanggihan dan kemajuan ilmu pengetahuan dan teknologi buatan manusia. Internet adalah singkatan dari Interconnected Networking yang apabila diartikan dalam Bahasa Indonesia berarti rangkaian komputer yang terhubung di dalam beberapa rangkaian jaringan. Sekolah merupakan wadah untuk menciptakan manusia yang bermutu dan berpendidikan. Siswa dan siswi berinteraksi di dalamnya menjadikan sekolah sebagai salah satu lingkungan bagi mereka dalam berkembang, bergaul dan belajar. Lingkungan sekolah yang baik akan menjadikan siswa-siswinya menjadi orang yang berguna sehingga banyak sekolah-sekolah yang menyediakan fasilitas yang terbaik untuk memfasilitasi kebutuhan siswanya, salah satunya yaitu menyediakan akses internet dengan mudah agar siswa-siswinya tidak ketinggalan seperti halnya pelajar di kota-kota besar dan negara-negara besar lain.

Penelitian terdahulu yaitu dari asniati, sudarmi suud $b$, jahada pada jurnal bening volume 4 nomor 1 januari 2020 dengan judul pengaruh penggunaan internet terhadap kenakalan remaja (siswa) tujuan penelitian adalah untuk mendeskripsikan dan menganalisis pengaruh penggunaan internet terhadap kenakalan remaja (siswa) sma negeri 2 tomia. Penelitian ini bersifat expost facto yang bertujuan untuk mencari informasi tentang hubungan sebab akibat dari suatu peristiwa. Populasi dalam penelitian ini adalah seluruh siswa kelas xi ips sma negeri 2 tomia yang terbagi 4 kelas yang berjumlah 125 orang sedangkan sampel penelitian sebanyak 32 orang yang diambil dengan menggunakan teknik purposive sampling. Teknik pengumpulan data yang digunakan dalam penelitian ini adalah angket yaitu angket penggunaan internet dan kenakalan remaja siswa. Dari hasil analisis data yaitu analisis regresi dapat disimpulkan bahwa ada pengaruh yang signifikan penggunaan internet siswa terhadap kenakalan remaja sma negeri 2 tomia. Hal ini menunjukan bahwa semakin tinggi penggunaan internet maka semakin tinggi pula kenakalan remaja siswa di sma negeri 2 tomia kabupaten wakatobi. Besarnya kontribusi penggunaan internet terhadap kenakalan remaja siswa di sma negeri 2 tomia adalah sebesar 32,8\% [1]

Penelitian yang sejenis juga di utarakan oleh mukti ratna dewi pada jurnal j. Ris. \& ap. Mat. Vol. 4 no. 1 (2020) pp. 17-27 jurnal riset dan aplikasi matematika e-issn: 2581-0154 Dengan judul klasifikasi akses internet oleh anak-anak dan remaja dewasa di jawa timur menggunakan support vector machine Pada tahun 2018 penetrasi pengguna internet di indonesia naik sebesar 10,12\% dibanding tahun sebelumnyan dengan pengguna terbanyak berada di pulau jawa yang mencapai 55\%. Kelompok usia pengguna internet terbanyak berturut-turut berada pada usia 15 hingga 19 tahun, umur 20 hingga 24 tahun, dan anak-anak yang berumur 5 hingga 9 tahun. Berdasarkan penelitian yang dilakukan oleh nurrahman (2017), faktorfaktor yang secara signifikan mempengaruhi penggunaan internet di jawa timur antara lain adalah umur, jenjang pendidikan, perbedaan tempat tinggal antara perkotaan dan pedesaan, status pekerjaan, perangkat yang digunakan dalam mengakses internet dalam tiga bulan terakhir serta kepemilikan bangunan. Untuk mengetahui besar tingkat pengguna internet maka perlu dilakukan pengelompokkan berdasarkan faktorfaktor yang mempengaruhinya. Oleh karena itu, penelitian ini melakukan klasifikasi akses internet oleh anak-anak dan remaja usia 6 hingga 21 tahun di jawa timur berdasarkan faktor-faktor yang signifikan menggunakan support vector machine (svm) dengan fungsi kernel radial basis fuction (rbf). Berdasarkan nilai auc sebesar 0,92, kinerja model svm yang terbentuk tergolong sangat bagus (excellent) dengan nilai akurasi, sensitivitas, dan spesifisitas berturut-turut sebesar 86,45\%; 84,64\% dan 88,63\% [2].

Fokus penelitian ini ialah bagaimana memodelkan klasifikasi dengan beberapa algoritma dalam studi kasus ini menerapkan algoritma naïve bayes untuk menganalisa hak akses internet siswa, dari penerapan metode tersebut dapat dilihat akurasi kemudian dapat menganalisa pemakaian berdasarkan umur.

\section{LANDASAN TEORI}

Internet adalah sebuah jaringan komunikasi public dan global yang menyediakan koneksi langsung kepada siapa saja melalui Local area network (LAN) dan Internet Service Provider (ISP) pengertian internet dalam arti sederhana adalah komunikasi antara konsumen, marketer, dan jutaan organisasi lainnya. Internet memungkinkan orang untuk menyesuaikan cara mereka berkomunikasi, apakah hanya dengan satu orang atau dengan seluruh target pasar, dengan cepat dan mudah. Internet mengarah pada 
jaringan fisik yang menghubungkan komputer-komputer di seluruh dunia. Internet terdiri dari infrastruktur jaringan server dan komunikasi widearea yang saling terhubung, digunakan untuk menyimpan dan mengirimkan informasi dalam jumlah yang besar melalui internet. Jadi, internet merupakan jaringan global yang menghubungkan pengguna komputer di seluruh dunia dengan menggunakan protokol standar dalam berkomunikasi yaitu protokol TCP/IP

Keuntungan Internet keuntungan dari internet dapat diringkas dengan istilah 6C, yang terdiri dari :

a. Cost Reduction Pengurangan kebutuhan penjualan dan pemasaran dapat ditangani melalui operator telepon dan pengurangan biaya cetak dan distribusi materi komunikasi pemasaran, semuanya dapat dipublikasikan melalui website.

b. Capability Internet menyediakan peluang baru untuk produk-produk dan layanan baru serta pencarian pangsa pasar baru.

c. Competitive advantage Jika sebuah perusahaan memperkenalkan kemampuan baru sebelum pesaingnya, maka perusahaan akan memperoleh keuntungan sebelum pesaingnya memiliki kemampuan yang sama.

d. Communications improvement Mencakup peningkatan komunikasi dengan pelanggan, pemasok, karyawan, dan distributor.

e. Control Internet dan intranet dapat menyediakan penelitian pemasaran yang lebih baik melalui pelacakan perilaku pelanggan dan cara staf perusahaan memberikan pelayanan.

f. Customer service improvement Dapat dicapai dengan menggunakan query database yang interaktif. Contohnya : ketersediaan stock atau pertanyaan-pertanyaan mengenai layanan pelanggan.

Data mining adalah suatu istilah yang digunakan untuk menemukan pengetahuan yang tersembunyi di dalam database. Data mining merupakan proses semi otomatik yang menggunakan teknik statistik, matematika, kecerdasan buatan, dan machine learning untuk mengekstrasi dan menidentifikasi informasi pengetahuan potensial dan berguna yang bermanfaat yang tersimpan di dalam database besar [3]. Data mining adalah kegiatan menemukan pola yang menarik dari data dalam jumlah besar, data dapat disimpan dalam database, data warehouse, atau penyimpanan informasi lainnya. Data mining berkaitan dengan bidang ilmu - ilmu lain, seperti database system, data warehousing, statistik, machine learning, information retrieval, dan komputasi tingkat tinggi. Selain itu, data mining didukung oleh ilmu lain seperti neural [6] network, pengenalan pola, spatial data analysis, image database, signal.

Klasifikasi adalah suatu fungsionalitas data mining yang menghasilkan model untuk memprediksi kelas atau kategori dari objek - objek didalam basis data. Klasifikasi merupakan proses yang terdiri dari dua tahap, yaitu tahap pembelajaran dan tahap pengklasifikasian. Pada tahap pembelajaran, sebuah algoritma klasifikasi akan membangun sebuah model klasifikasi dengan cara menganalisis training data. Tahap pembelajaran dapat juga dipandang sebagai tahap pembentuakan fungsi atau pemetaan $\mathrm{Y}=\mathrm{F}(\mathrm{X})$ dimana $\mathrm{Y}$ adalah kelas hasil prediksi dan $\mathrm{X}$ adalah tuple yang ingin diprediksi kelasnya. Selanjutnya pada tahap pengklasifikasian, model yang telah dihasilkan akan digunakan untuk melakukan pengklasifikasian. klasifikasi adalah proses pencarian sekumpulan model yang menggambarkan dan membedakan kelas data dengan tujuan agar model tersebut dapat digunakan untuk memprediksi kelas dari suatu obyek yang belum diketahui kelasnya. Naïve Bayes merupakan salah satu metode machine learning yang menggunakan perhitungan probabilitas. Konsep dasar yang digunakan oleh Naïve bayes adalah Teorema Bayes, yaitu melakukan klasifikasi dengan melakukan perhitungan nilai probabilitas $p C c D d(\mid)==i j$, yaitu probabilitas kategori $c i$ jika diketahui dokumen $d j$. Klasifikasi dilakukan untuk menentukan kategori $c \varepsilon C$ dari suatu dokumen $d \varepsilon D$ dimana $C=\{c 1, c 2, c 3, \ldots, c i\}$ dan $D=\{d 1, d 2, d 3, \ldots, d j\}$. Penentuan dari kategori sebuah dokumen dilakukan dengan mencari nilai maksimum dari $p C$ c $D d(\mid)==i j$ pada $P=\{p C c D$ $d(\mid)==i j \mid c \& C$ dan $d \& D\}$. Nilai probabilitas $p C c D d(\mid)==i j$ dapat dihitung dengan persamaan dengan $p D d C c(\mid)==j i$ merupakan nilai probabilitas dari kemunculan dokumen $d j$ jika diketahui dokumen tersebut berkategori $c i, p C c()=i$ adalah nilai probabilitas kemunculan kategori $c i, \operatorname{dan} p D d($ )$=j$ adalah nilai probabilitas kemunculan dokumen $d j$. Naïve Bayes menganggap sebuah dokumen sebagai kumpulan dari kata-kata yang menyusun dokumen tersebut, dan tidak memperhatikan urutan 
kemunculan kata pada dokumen, sehingga perhitungan probabilitas $p D d C c(\mid)==j i$ dapat dianggap sebagai hasil perkalian dari probabilitas kemunculan kata-kata pada dokumen $d j$. Sebuah dokumen dapat dituliskan sebagai $d j=\{w 1 j, w 2 j, w 3 j, \ldots, w k j\}$, sehingga probabilitas $p C c D d(\mid)==i j$ dapat dituliskan

Rapidminer merupakan platform perangkat lunak yang dikembangkan oleh perusahaan dengan nama yang sama, yang menyediakan lingkungan terpadu untuk pembelajaran mesin (machine learning), pembelajaran mendalam (deep learning), penambangan text (text mining), dan analisis prediktif (predictive analytic). Aplikasi ini digunakan untuk aplikasi bisnis dan komersial serta untuk penelitian, pendidikan, pelatihan, pembuatan prototype dengan cepat, dan pengembangan aplikasi serta mendukung semua langkah proses pembelajaran mesin termasuk persiapan data, visualisasi hasil, validasi dan pengoptimalan.[3]

\section{Metode Penelitian}

Adapun teknik pengumpulan data merupakan suatu cara yang dilakukan oleh peneliti untuk memperoleh data-data yang diperlukan. Dalam penelitian ini teknik yang digunakan antara lain sebagi berikut :

1. Survey

Survey penelitian dilakukan dengan meminta ijin kepada kepala sekolah menengah atas 1 negeri plumbon

2. Sumber data

Sumber data pada penelitian ini menggunakan Data Primer

Metode analisis data yang digunakan di penelitian ini adalah analisis deskriptif dalam menyeleksi data kuantitatif. Dalam fungsinya analisis deskriptif digunakan untuk mendeskripsikan atau memberi gambaran dari data yang terkumpul dari fakta fakta yang ada, data yang dimaksud adalah data sekunder yang berupa data kuantitatif yang bentuk angka-angka dapat digunakan untuk operasi matematika.

Metode pengembangan data mining yang digunakan untuk menganalisis data dalam penerapan data mining ini menggunakan proses tahapan knowledge discovery in databases (KDD) yang terdiri dari Data, Data Cleaning, Data transformation, Data mining, Pattern evolution, knowledge.

berikut merupan hal - hal yang perlu di lakukan dalam penelitian berdasarkan tahapan knowledge discovery in databases :

1. Data

Data merupakan sekumpulan data operasional yang diperlu sebelum dilakukan sebelum tahap penggalian informasi dalam Knowledge Discovery Database (KDD) dimulai.

2. Data Cleaning

Proses data cleaning merupakan proses Pembersihan data yang bertujuan untuk menghilangkan data yang tidak memiliki nilai (null), data yang salah input, data yang tidak relevan, duplikat data dan data yang tidak konsisten

3. Data transformation

Data transformation dilakukan dengan memberikan inisialisasi terhadap data yang memiliki nilai nominal menjadi bernilai numerik.

4. Data Mining.

Pada fase ini yang dilakukan adalah menerapkan algoritma atau metode pencarian pengetahuan. Ini adalah langkah penting di mana teknik kecerdasan diterapkan untuk mengekstrak pola informasi yang berpotensi berguna dari data yang dipilih.

5. evaluation

Pada tahap evaluasi, akan diketahui apakah hasil daripada tahap data mining dapat menjawab tujuan yang telah ditetapkan. Untuk itu akan dilakukan profilisasi pada setiap cluster yang telah terbentuk, untuk diketahui karakteristik pada kelompok tersebut. Disamping itu untuk diketahui kesesuaian dengan jalur perminatan akan dilakukan analisis lebih lanjut untuk dihubungkan dengan atribut 
perminatan, Sehingga diharapkan mendapatkan informasi atau pola yang berguna sebagai acuan pemutakhiran data.

6. Knowledge

Tahap terakhir dari proses data mining adalah bagaimana memformulasikan keputusan atau aksi dari hasil analisis yang didapat.

\section{HASIL DAN PEMbahasan}

Populasi pada penelitian ini yang dilakukan pada sekolah menengah atas negeri 1 plumbon kabupaten cirebon dengan menggunakan kelas X (Sepuluh), Kelas XI (Sebelas) dan Kelas XII (Dua Belas) dengan jumlah siswa perempuan sebanyak 632 dan siswa laki laki sebanyak 266 jadi total siswa sebanyak 898 siswa. Simple random sampling atau pengambilan sampel acak sederhana adalah teknik penarikan sampel yang memberikan kesempatan yang sama bagi setiap anggota populasi. Teknik sampling yang digunakan pada penelitian ini menggunakan random sampling artinya mengambil beberapa sample dari kelompok kelas X (Sepuluh) sebanyak 90 sample, Kelas XI (Sebelas) sebanyak 90 sample dan Kelas XII (Dua Belas) sebanyak 90 sample. Maka sample yang digunakan adalah sebanyak 270.

Data preprocesing bertujuan untuk menganalisa data dari kuisoner yang telah diisi oleh siswa, dengan beberapa atribut umur, jenis kelamin, kelas, apakah menggunakan handphone di 3 bulan terakhir, apakah menggunakan laptop di 3 bulan terakhir, apakah mengakses internet. Dari data tersebut di peroleh sebagai berikut :

Tabel 1 Data Keinginan konsumen

\begin{tabular}{|c|c|c|c|c|c|c|c|}
\hline No & Umur & Jenis Kelamin & Kelas & $\begin{array}{c}\text { Tempat } \\
\text { tinggal }\end{array}$ & gunakan HP & Gunakan Laptop & $\begin{array}{c}\text { Akses } \\
\text { Internet }\end{array}$ \\
\hline 1 & 17 & Laki Laki & 10 & Pedesaan & tidak & ya & ya \\
\hline 2 & 17 & Perempuan & 10 & Perkotaan & ya & ya & tidak \\
\hline 3 & 18 & Perempuan & 11 & Pedesaan & tidak & ya & ya \\
\hline 4 & 19 & Laki Laki & 12 & Perkotaan & ya & tidak & ya \\
\hline 5 & 17 & Perempuan & 10 & Perkotaan & ya & ya & tidak \\
\hline 6 & 17 & Perempuan & 10 & Perkotaan & ya & ya & tidak \\
\hline 7 & 18 & Perempuan & 11 & Pedesaan & tidak & ya & ya \\
\hline 8 & 17 & Perempuan & 10 & Pedesaan & ya & ya & ya \\
\hline 9 & 17 & Laki Laki & 10 & Perkotaan & tidak & tidak & tidak \\
\hline 10 & 18 & Perempuan & 11 & Pedesaan & tidak & tidak & tidak \\
\hline$\ldots$ & $\ldots . .$. & $\ldots . .$. & $\ldots$. & $\ldots$. & $\ldots$ & $\ldots$ \\
\hline
\end{tabular}

Untuk mempermudah proses menganalisa data menggunakan algorita naïve bayes maka perlu dilakukan data cleaning atau preprocesing, dengan tujuan menghilangkan noise atau missing value. Dari preprocesing dari data sebanyak 270 maka yang dapat digunakan ialah 196 dari 196 tersebut 70\% akan dijadikan dataset latih dan 305 dijadikan dataset uji.

Data transformation dilakukan dengan memberikan inisialisasi terhadap data yang memiliki nilai nominal menjadi bernilai numerik. Pada penelitian ini mengganti jenis type data menjadi integer bertujuan untuk memudahkan dalam pengelompokan.

Data yang sudah diolah kemudian diuji dengan menggunakan aplikasi rapidminer. 


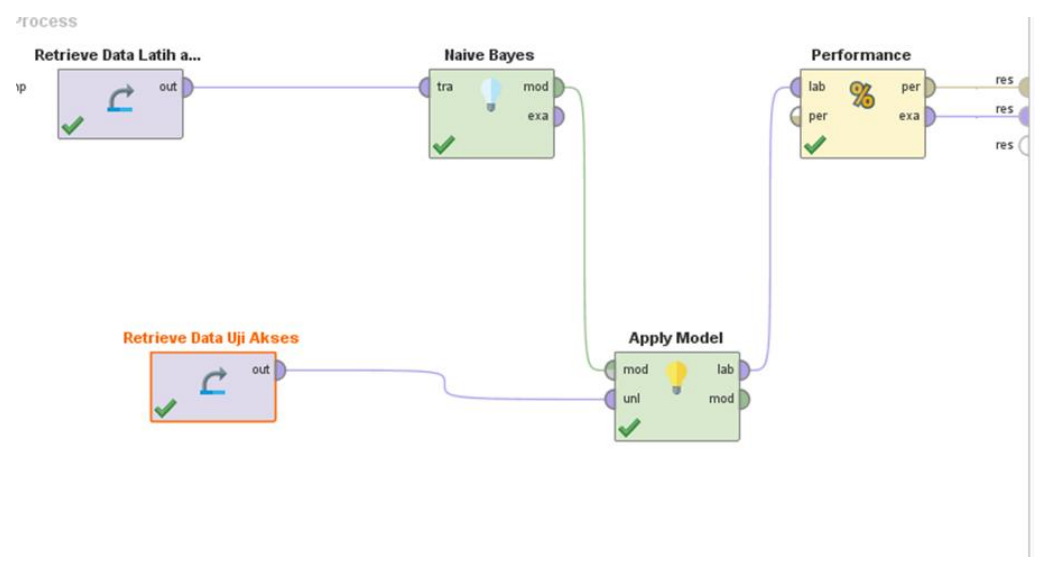

Gambar 1 Desain Datamining

Berdasarkan gambar diatas menjelaskan bahwa proses desain datamining, pada tahap ini ialah melakukan drag and drop data set yang ada di repository ke dalam menu bar proses.

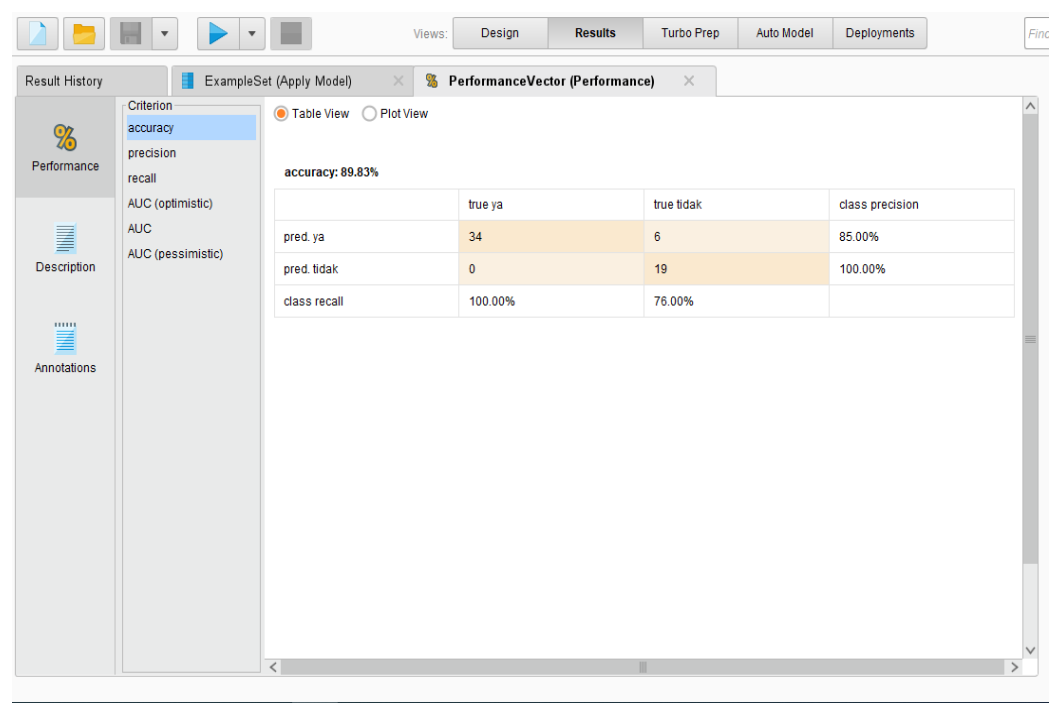

Gambar 2 Hasil Akurasi

Berdasarkan gambar di atas menjelaskan bahwa akurasi pada penelitian ini sebesar 89,83\% dengan rincian detail sebagai berikut :
a. Hasil Prediksi Ya dan ternyata Ya sebanyak 34.
b. Hasil Prediksi Ya dan ternyata Tidak sebanyak 6.
c. Hasil Prediksi tidak dan ternyata Ya sebanyak 0.
d. Hasil Prediksi tidak dan ternyata tidak sebanyak 19. 
Tabel . Nilai Confidence

\begin{tabular}{|c|c|c|c|c|c|c|c|c|c|c|}
\hline No & $\begin{array}{c}\text { gunakan } \\
\text { HP }\end{array}$ & $\begin{array}{c}\text { prediction } \\
\text { (gunakan HP) }\end{array}$ & $\begin{array}{c}\begin{array}{c}\text { confidence } \\
\text { (tidak) }\end{array} \\
\end{array}$ & confidence (ya) & Umur & Jenis Kelamin & Kelas & \begin{tabular}{|c|} 
Tempat \\
tinggal
\end{tabular} & $\begin{array}{c}\text { Gunakan } \\
\text { Laptop }\end{array}$ & $\begin{array}{c}\text { Akses } \\
\text { Internet }\end{array}$ \\
\hline 1 & ya & ya & $\begin{array}{l}0.02501981 \\
5842730535\end{array}$ & 0.9749801841572695 & 17.0 & Perempuan & 10.0 & Perkotaan & ya & ya \\
\hline 2 & ya & ya & \begin{tabular}{|l|}
0.02971781 \\
0303436537
\end{tabular} & 0.9702821896965634 & 17.0 & Perempuan & 10.0 & Perkotaan & tidak & tidak \\
\hline 3 & ya & ya & $\begin{array}{l}0.01680561 \\
4742974602\end{array}$ & 0.9831943852570253 & 19.0 & Laki Laki & 12.0 & Perkotaan & tidak & ya \\
\hline 4 & tidak & tidak & $\begin{array}{c}0.93307312 \\
5043363 \\
\end{array}$ & 0.06692687495663693 & 18.0 & Perempuan & 11.0 & Pedesaan & ya & ya \\
\hline 5 & ya & ya & \begin{tabular}{|r|}
0.01878439 \\
3183640818
\end{tabular} & 0.9812156068163592 & 17.0 & Perempuan & 10.0 & Perkotaan & ya & tidak \\
\hline 6 & tidak & tidak & $\begin{array}{c}0.93307312 \\
5043363\end{array}$ & 0.06692687495663693 & 18.0 & Perempuan & 11.0 & Pedesaan & ya & ya \\
\hline 7 & ya & ya & \begin{tabular}{|c|}
0.29546174 \\
75278215 \\
\end{tabular} & 0.7045382524721785 & 17.0 & Perempuan & 10.0 & Pedesaan & ya & ya \\
\hline 8 & ya & ya & $\begin{array}{l}0.02971781 \\
0303436537\end{array}$ & 0.9702821896965634 & 17.0 & Perempuan & 10.0 & Perkotaan & tidak & tidak \\
\hline 9 & ya & ya & $\begin{array}{l}0.01680561 \\
4742974602\end{array}$ & 0.9831943852570253 & 19.0 & Laki Laki & 12.0 & Perkotaan & tidak & ya \\
\hline 10 & tidak & tidak & $\begin{array}{c}0.93307312 \\
5043363 \\
\end{array}$ & 0.06692687495663693 & 18.0 & Perempuan & 11.0 & Pedesaan & ya & ya \\
\hline$\ldots$. & $\ldots$ & $\ldots$ & $\ldots$ & $\ldots$ & $\ldots$ & $\ldots$ & $\ldots$ & $\ldots$ & $\ldots$ & $\ldots$ \\
\hline
\end{tabular}

Berdasarkan tabel diatas menjelasan Data statistik hasil dari penerapan algoritma naive bayes menjelaskan yang tidak ke tidak sebanyak 19 siswa, dari data 19 tersebut terdiri dari rata-rata umur 18 tahun. Kemudian rata-rata yang tidak ke tidak menggunakan internet yang jenis kelaminnya mayoritas atau seluruh adalah perempuan. Rata-rata yang tidak ke tidak menggunakan internet adalah kelas XI (sebelas). Sedangkan mayoritas alamatnya pedesaan.

Data statistik hasil dari penerapan algoritma naive bayes menjelaskan yang tidak ke ya sebanyak 6 siswa, dari data 6 tersebut terdiri dari rata-rata umur 17 tahun. Kemudian rata-rata yang tidak ke ya menggunakan internet yang jenis kelaminnya mayoritas atau seluruh adalah Laki Laki. Rata-rata yang tidak ke ya menggunakan internet adalah kelas X (sepuluh). Sedangkan mayoritas alamatnya perkotaan.

Data statistik hasil dari penerapan algoritma naive bayes menjelaskan yang ya ke ya sebanyak 34 siswa, dari data 34 tersebut terdiri dari rata-rata umur 17 tahun sebanyak 27 siswa dan umur 19 tahun sebanyak 7 siswa. Kemudian rata-rata yang ya ke ya menggunakan internet yang jenis kelaminnya laki laki sebanyak 7 dan Perempuan Sebanyak 19 siswa. Rata-rata yang ya ke ya menggunakan internet adalah kelas X (sepuluh) sebanyak 27 siswa dan kelas 12 sebanyak 7 siswa. Sedangkan mayoritas alamatnya perkotaan sebanyak 18 dan alamat dari pedesaan sebanyak 6.

\section{KESIMPULAN}

Dari hasil penelitian yang telah dilakukan, penulis dapat menarik beberapa kesimpulan sebagai berikut

a. Penerapan model klasifikasi metode naive bayes adalah sebagai berikut: 1) Menginput data latih pada rapid miner, 2) Melakukan Data Selection \& Cleaning, 3) Melakukan Data Transformation, 4) Mengolah Data Mining, 5) Melakukan Interprotation.

b. Akurasi pada penelitian ini sebesar $89.83 \%$ sebagai berikut: 1) Hasil Prediksi Ya dan ternyata Ya sebanyak 34. Hasil Prediksi Ya dan ternyata Tidak sebanyak 6. Hasil Prediksi tidak dan ternyata Ya sebanyak 0. Hasil Prediksi tidak dan ternyata tidak sebanyak 19,2) hasil dari prediksi dengan uji 59 data baru maka mendapatkan hasil ya sebanyak 40 siswa dan tidak ada 19 siswa.

c. 
JURSISTEKNI (Jurnal Sistem Informasi dan Teknologi Informasi) Vol 4, No.1, January 2022: Hal 1- 8 ISSN.

P: 2715-1875, E: 2715-1883

\section{DAFTAR PUSTAKa}

Format dasar untuk buku:

[1] Asosiasi Penyelenggara Jasa Internet Indonesia (APJII), "Survei APJII yang Ditunggutunggu, Penetrasi Internet Indonesia 2018," Buletin APJII, p. 1, Mei 2020

[2] Asosiasi Penyelenggara Jasa Internet Indonesia, "Penetrasi dan Profil Perilaku Pengguna Internet di Indonesia," Asosiasi Penyelenggara Jasa Internet Indonesia, Jakarta, Infografis 2019.

[3] Ryan R. Nurrahman, "Analisis Faktor-Faktor yang Mempenharuhi Kepala Rumah Tangga Jawa Timur dalam Mengakses Internet Tahun 2017," Institut Teknologi Sepuluh Nopember, Surabaya, Tugas Akhir 2017.

[4] Octavia Dian Pratama Nia Anggraini, "Analisis Faktor-Faktor yang Mempengaruhi Anak-Anak dan Remaja di Jawa Timur Dalam Mengakses Internet Menggunakan Regresi Logistik Biner," Institut Teknologi Sepuluh Nopember, Surabaya, Tugas Akhir 2019. 2018.

[5] Budi Santosa, Data Mining : Teknik Pemanfaatan Data untuk Keperluan Bisnis/Studi, 1st ed. Yogyakarta: Graha Ilmu, 2007.

[6] Darmawan, Rudi. (2008). Modul Teknologi Informasi dan Komunikasi. Solo: Hayati.

[7] Gunarsa, Singgih. (2004). Psikologi Perkembangan Anak dan Remaja. Jakarta: BPK Gunung Mulia.

[8] Haryono, H. (2012). Mendayagunakan Internet, Edisis Revisi. Surabaya: Hi-Fest Publishing.

[9] Haryono, H (2006). Mendayagunakan Internet. Surabaya: Hi-Fest Publishing. 